\title{
Thermal Hydraulic Analysis Using GIS on Application of HTR to Thermal Recovery of Heavy Oil Reservoirs
}

\author{
Yangping Zhou, Fu Li, Zhiwei Zhou, and Yuanle Ma \\ Institute of Nuclear and New Energy Technology, Tsinghua University, Beijing 100084, China \\ Correspondence should be addressed to Zhiwei Zhou, zhouzhw@mail.tsinghua.edu.cn
}

Received 9 March 2012; Revised 26 August 2012; Accepted 9 October 2012

Academic Editor: Carlo Sborchia

Copyright (๑) 2012 Yangping Zhou et al. This is an open access article distributed under the Creative Commons Attribution License, which permits unrestricted use, distribution, and reproduction in any medium, provided the original work is properly cited.

\begin{abstract}
At present, large water demand and carbon dioxide $\left(\mathrm{CO}_{2}\right)$ emissions have emerged as challenges of steam injection for oil thermal recovery. This paper proposed a strategy of superheated steam injection by the high-temperature gas-cooled reactor (HTR) for thermal recovery of heavy oil, which has less demand of water and emission of $\mathrm{CO}_{2}$. The paper outlines the problems of conventional steam injection and addresses the advantages of superheated steam injection by HTR from the aspects of technology, economy, and environment. A Geographic Information System (GIS) embedded with a thermal hydraulic analysis function is designed and developed to analyze the strategy, which can make the analysis work more practical and credible. Thermal hydraulic analysis using this GIS is carried out by applying this strategy to a reference heavy oil field. Two kinds of injection are considered and compared: wet steam injection by conventional boilers and superheated steam injection by HTR. The heat loss, pressure drop, and possible phase transformation are calculated and analyzed when the steam flows through the pipeline and well tube and is finally injected into the oil reservoir. The result shows that the superheated steam injection from HTR is applicable and promising for thermal recovery of heavy oil reservoirs.
\end{abstract}

\section{Introduction}

Steam injection $[1-3]$ is the most widely used and the most efficient process available today among the various enhanced oil recovery techniques currently being employed in heavy oil reservoirs and tar sand deposits. At present, fossil fuel such as oil, coal, and natural gas is burned to provide the energy to steam. Mostly, wet steam is adopted as the injection medium. The relatively large water demand and carbon dioxide $\left(\mathrm{CO}_{2}\right)$ emissions have emerged as challenges of the steam injection for thermal recovery [4]. Superheated steam, compared with wet steam, has higher heat content and specific volume, by which for steam stimulation not only can the bottom hole steam quality and steam swept volume be increased, but also it is characterized by higher viscosity breaking, heat expansion, blocking, crude oil distillation rate, and oil displacement $[5,6]$.

The High-Temperature Reactor (HTR) [7-10] has a distinct advantage in inherent safety, economics potential, high efficiency and potential usage for process heat application.
The Chinese Module High-Temperature Gas-cooled Reactor (MHTGR), named High-Temperature gas-cooled ReactorPebble bed Module (HTR-PM) [11-13], based on the technology and experience of the $10 \mathrm{MW}$ High-Temperature gas-cooled Reactor (HTR-10) $[14,15]$, will be started in the end of 2012 or later. The demonstration HTR-PM plant has two reactor modules, two steam generators, and one steam turbine which employ superheated steam as the driver power. The helical-coiled once through steam generator can produce the superheated steam. USA utility Entergy completed an economic analysis of using a HTGR (High-Temperature Gas-cooled Reactor) to generate hydrogen and process heat, and also electricity [16]. This study indicates that the cost of process heat or high-temperature steam produced by a HTGR can be competitive with the steam produced by normal fossil plant.

In this paper, the design of the secondary loop after the steam generator of the HTR-PM is modified to fit the need of steam injection for thermal recovery. The superheated steam produced by the steam generator is divided into two 
branches. The main fluid is applied for steam injection of the heavy oil reservoirs and the other fluid will flow into a twostage steam jet mixer in order to preheat the inlet water of the steam generator.

In order to analyze the thermal hydraulic behavior of the HTR-PM for heavy oil thermal recovery, a Geographic Information System (GIS) embedded with thermal hydraulic analysis function is designed and developed. Then it is applied to analyze the thermal hydraulic process in a reference heavy oil field where two kinds of injection are considered and compared: wet steam injection by boiler and superheated steam injection by HTR-PM. The heat loss, pressure change, and possible phase transformation are calculated and analyzed when the steam flows through the pipeline and well tube and is finally injected into oil reservoirs. Two kinds of pipeline are considered: overground and underground. Four kinds of oil well structure are included: heat insulation tube with packer, heat insulation tube without packer, normal tube with packer, and normal tube without packer. Calculation results indicate that the superheated steam injection by HTR-PM is applicable and has obviously higher quality of steam stimulation than the wet steam injection by the conventional boiler. Namely, under the same mass flow rate, the steam injection by HTRPM has characteristics of higher temperature, more enthalpy and larger specific volume than the wet steam injection by conventional boiler. Therefore, it will result in more intensive physical and chemical reactions between reservoir fluid and minerals, higher reduction of oil viscosity, and bigger expansion of crude oil volume, and so forth.

Section 2 of this paper introduces the modified HTRPM design and strategy when it is applied to heavy oil thermal recovery of an oil field. Section 3 describes the GIS system which is embedded with thermal hydraulic analysis function. Section 4 explains the process and result of the thermal hydraulic analysis of superheated steam injection by HTR and its comparison with wet steam injection by boiler. Section 5 describes the conclusions of this paper.

\section{HTR-PM for Heavy Oil Thermal Recovery}

2.1. General Description of HTR-PM. The HTR-PM deploys two pebble-bed modular HTRs each with $250 \mathrm{MW}$ thermal power. Two reactor modules are coupled with two steam generators which are connected to one steam turbine generator with $210 \mathrm{MW}$ electric power. The reactor and the steam generator are installed inside two separate pressure vessels. The pressure vessels are assembled in a staggered, side-by-side arrangement and are connected by a horizontal coaxial hot gas duct. The primary pressure boundary consists of the Reactor Pressure Vessel (RPV), the Steam Generator Pressure Vessel (SGPV), and the Hot gas Duct Pressure Vessel (HDPV), which all are housed in a concrete shielding cavity as shown in Figure 1. The main design parameters are listed in Table 1.

As shown in Figure 1, the thermal-hydraulic process related with the reactor and the primary loop of HTR-PM can be mainly explained as follows.

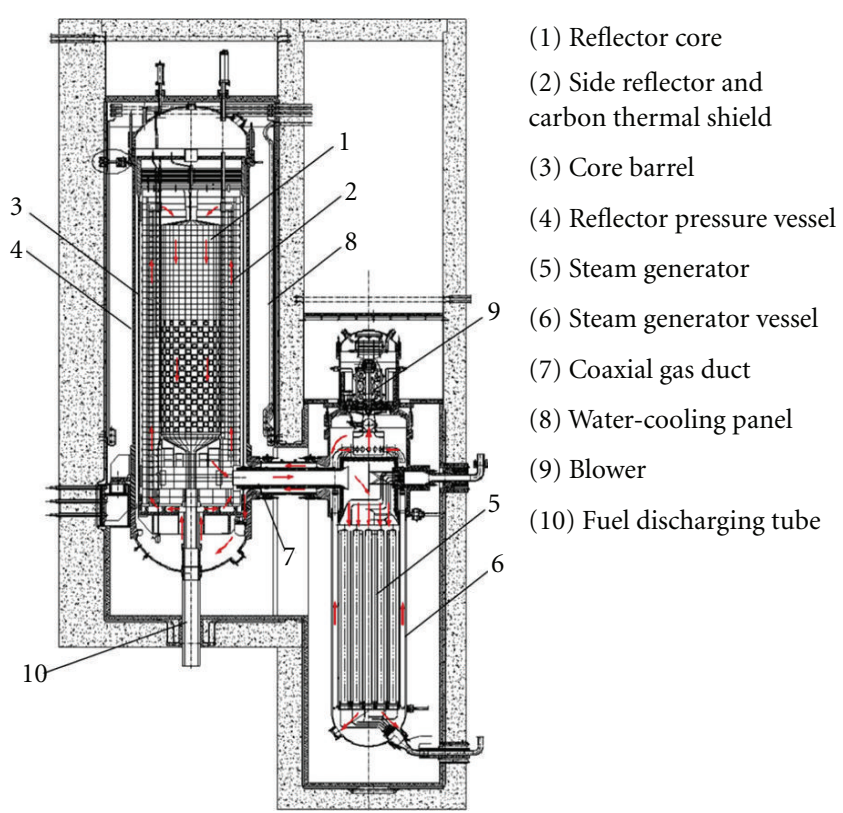

Figure 1: Primary loop of HTR-PM.

(i) Before entering the reactor vessel, the helium gas is driven by the helium blower, and the temperature of the inlet gas is around $250^{\circ} \mathrm{C}$. After the helium flows through the hot fuel spheres in the reactor core, the temperature of it reaches $750^{\circ} \mathrm{C}$. The hot helium exits the reactors and flows through the hot gas duct. The hot helium releases its thermal power to the water in the steam generator where it is cooled down to around $250^{\circ} \mathrm{C}$. Then, the helium blower blows the cold helium through the outer coaxial pipes of the hot gas duct. Finally, the cold helium flows into RPV where it is heated again. In this way, a cycle of the helium flow is completed in the primary loop.

(ii) At the side of the secondary loop of HTR-PM plant, the water at a temperature of $205^{\circ} \mathrm{C}$ in the steam generator is heated to $566^{\circ} \mathrm{C}$ by hot helium and becomes superheated steam. Then superheated steam with a pressure of $14.3 \mathrm{MPa}$ will drive the steam turbine and its conjoined generator in order to generate electrical power based on the Rankine cycle.

2.2. Status and Existing Problems of Conventional Steam Injection for Thermal Recovery. Steam injection is an established thermal recovery technique that has been applied successfully on many heavy oil reservoirs around the world. The process started in early 1960s with cyclic steam injection. The three main methods of steam injection are Cyclic Steam Stimulation (CSS), Steam Drive (SD), and Steam Assisted Gravity Drainage (SAGD) [2].

The CSS is a simple and cheap method of applying thermal recovery process on a reservoir. It involves injecting steam into a well for several weeks, shutting the well in as long as necessary to allow the steam to heat the oil in the areas around the well, and putting the well back on 
TABLE 1: Major design parameters of HTR-PM [17].

\begin{tabular}{lc}
\hline Item & Value \\
\hline Thermal power $(\mathrm{MW})$ & $2 \times 250$ \\
Electric power $(\mathrm{MW})$ & 210 \\
Active core diameter $(\mathrm{cm})$ & 300 \\
Equivalent active core height $(\mathrm{cm})$ & 1100 \\
Primary helium pressure $(\mathrm{MPa})$ & 7.0 \\
Average helium temperature at reactor & $250 / 750$ \\
inlet/outlet $\left({ }^{\circ} \mathrm{C}\right)$ & \\
Helium mass flow rate at full power & 96 \\
(kg. $\left.\mathrm{s}^{-1}\right)$ & Once-through \\
Type of steam generator & helical \\
& 98 \\
Main steam flow rate at the inlet of & \\
turbine $\left(\mathrm{kg} \cdot \mathrm{s}^{-1}\right)$ & 14.3 \\
Main steam pressure $(\mathrm{MPa})$ & 566 \\
Main steam temperature $\left({ }^{\circ} \mathrm{C}\right)$ & 205 \\
Main feed-water temperature $\left({ }^{\circ} \mathrm{C}\right)$ &
\end{tabular}

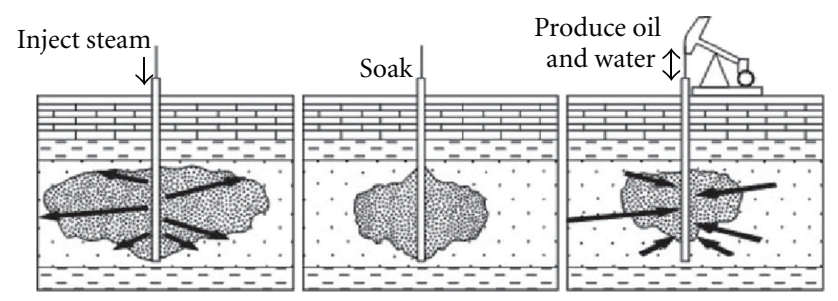

Figure 2: Cyclic steam stimulation process.

production to recover the heated oil (Figure 2). This process is repeated when the production from the well declines to a low level. The cycle is repeated many times until the ratio of oil produced to steam injected named Oil-Steam Ratio (OSR) drops to a level that is considered uneconomic. CSS was the first steam injection technique used in heavy oil reservoirs. It can be used as a limited pilot test on a well to investigate whether steam injection can enhance oil recovery in a particular field before undertaking more expensive pattern pilot tests that will require more wells and more equipment.

The scenario of the conventional thermal recovery technology uses the boiler to generate wet steam, which is shown as the bottom part of Figure 3 .

Conventionally, the boiler using fossil fuel such as coal, natural gas, and oil is utilized to heat water to wet steam for thermal recovery of heavy oil reservoirs. The water is driven by a pump and softened by the water-softening plant before entering the boiler. The steam out of the boiler will flow through the pipeline to a steam injecting station near the heavy oil well. Then, the wet steam will pass through the well head to the well tube. Finally, the wet steam will flow into the oil reservoir via the well tube which is usually several hundred meters long.

Because of the limited thermal power of boilers and heat loss during steam transportation, the boilers are built near the heavy oil well to provide enough steam for thermal recovery. One boiler can only provide steam to a limited number of oil wells for steam injection. Usually, there are many boilers in a heavy oil field to provide steam to different heavy oil wells.

The specific enthalpy of the steam or water can be indicated as

$$
h(P, T, x)=h^{\prime}(P)+x Q(P)+x \int_{T_{P}}^{T} C_{P}^{\prime \prime} d t,
$$

where $P$ is the pressure of steam or water; $T$ is the temperature of steam or water; $x$ is the dryness of steam or water; $h^{\prime}(P)$ is the specific enthalpy of the saturated water at pressure $P ; Q(P)$ is the latent heat of vaporization of water at pressure $P ; T_{P}$ is the temperature of the saturated steam at pressure $P . C_{P}^{\prime \prime}$ is the specific heat of the superheated steam at pressure $P$.

The dryness $x$ of wet steam can be expressed as

$$
x=\frac{m_{s}}{m_{w}},
$$

where $m_{s}$ is the mass of the steam component in the wet steam; $m_{w}$ is the mass of the whole wet steam.

The conventional thermal recovery technology with dispersed steam supply and wet steam injection has the following shortcomings.

(i) The operation and management of a large number of small boilers is very expensive because of high labor expenditure and relative high price of equipment [18].

(ii) The conventional boiler is burning fossil fuel such as coal, natural gas, and oil to generate the steam, which has an environmental challenge of carbon dioxide emissions and large demand of water [4].

(iii) Loss of heat during steam transportation will reduce the heat capacity of injected steam and obviously worsen its quality since the velocity of flow is relatively slow and the specific enthalpy is low. Therefore, the heavy oil reservoirs cannot gain enough thermal energy even if a lot of water is consumed $[5,6]$.

(iv) The wet steam has low temperature and low specific volume which result in low stimulation efficiency [5, $6]$.

2.3. Strategy of Superheated Steam Injection from HTR$P M$. The strategy of superheated steam injection by HTR$\mathrm{PM}$ is shown as the top part of Figure 3. Unlike the conventional steam injection method, all superheated steam will be intensively produced by one HTR plant which is located at several kilometers away from the heavy oil field in consideration of safety and engineering requirements. Then, the superheated steam will be delivered all over to the whole heavy oil field through the main steam pipeline with bigger pipe diameter and higher thermal insulation ability. The main steam pipeline will connect to normal pipelines at the diverging points. Finally, the steam will flow into the oil 


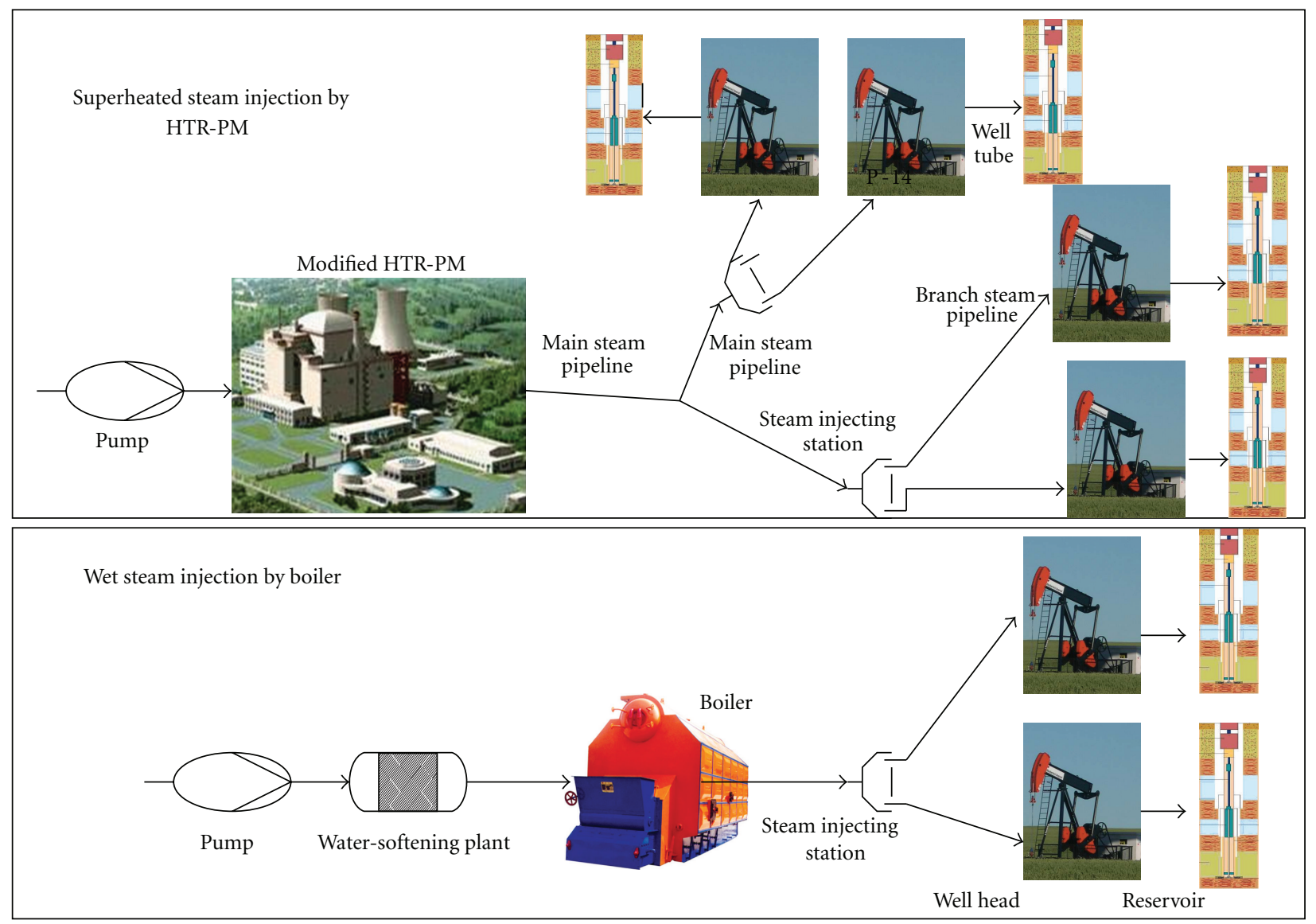

FIGURE 3: Strategies for steam injection by HTR-PM and boiler.

reservoirs through the steam injecting station, well head, and well tube.

For the wet steam, $x$ is less than 1 and the third part of (1) is zero. For the superheated steam, $x$ is 1 . Therefore, the enthalpy difference between the superheated steam and the wet steam at the same pressure can be shown as follows:

$$
h(P, T)-h\left(P, T_{P}, x\right)=(1-x) Q(P)+\int_{T_{P}}^{T} C_{P}^{\prime \prime} d t .
$$

From this equation, it can be found that the superheated steam has much more enthalpy than the wet steam when $x$ is not very close to 1 and $T_{P}-T$ is a big value. The thermal recovery technology by HTR with concentrated steam supply and superheated steam injection is predicted to have the following advantages.

(i) The operation and management of HTR for steam generation is relatively cheap.

(ii) The steam production by HTR emits less $\mathrm{CO}_{2}$ than the conventional boiler burning fossil fuel.

(iii) Loss of heat during steam transportation will not seriously worsen the quality of injected steam since the velocity of flow is relatively fast and the specific enthalpy is high. Therefore, the heavy oil reservoirs can receive much more thermal energy by superheated steam injection when the same mass of water is injected into oil reservoirs.

(iv) The superheated steam has higher enthalpy and higher specific volume which results in higher quality of steam stimulation $[5,6]$.

2.4. Adoption of HTR-PM for Heavy Oil Thermal Recovery. The design of the HTR-PM applied to thermal recovery of heavy oil reservoirs is shown in Figure 4. The primary loop and the steam generator are kept as the original design of the HTR-PM in order to take advantage of its mature design. Originally, the secondary loop of the HTR-PM adopts a steam turbine system which generates electricity with a Rankine cycle. A two-stage steam jet mixer system is design to preheat the feed water of the HTR-PM.

In the secondary loop of HTR-PM, some basic parameters such as mass flow rate, inlet temperature, and outlet temperature of water should be determined by taking into account the original design of HTR-PM and need of heavy oil thermal recovery. Table 2 shows the basic configuration when a HTR-PM or boilers are applied to thermal recovery of a reference heavy oil field. In order to maintain the safety of HTR-PM and oil field, the HTR-PM is located around $4 \mathrm{~km}$ away from the oil field to void the interaction when 


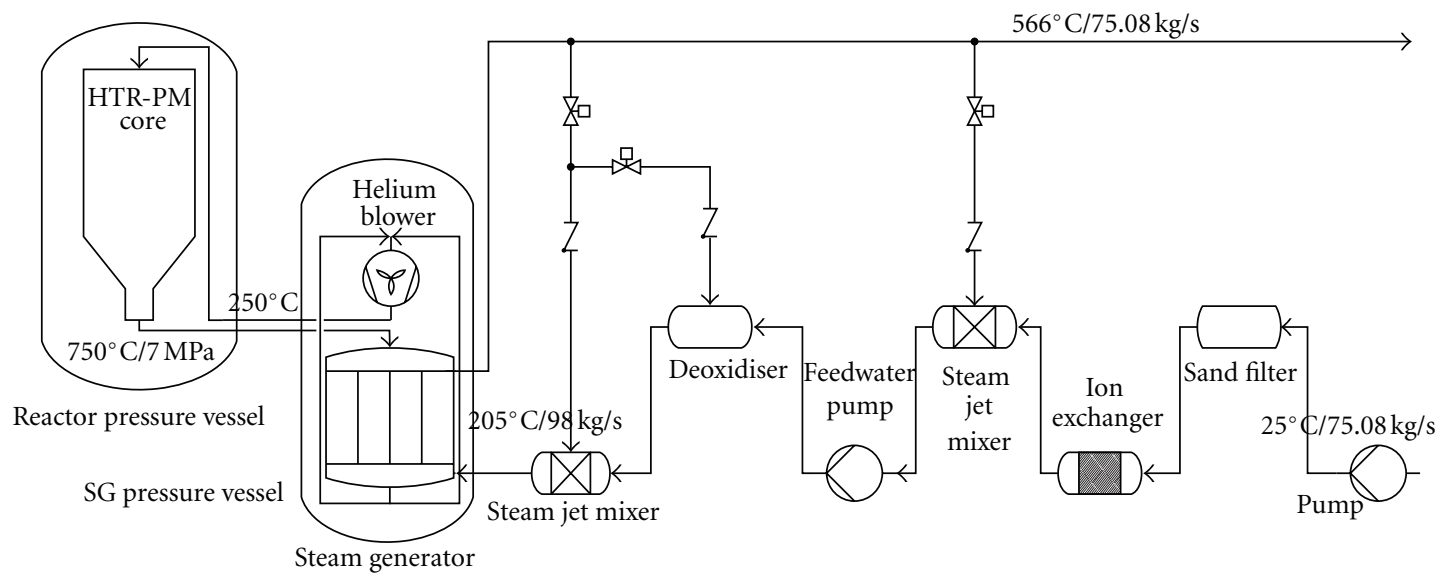

Figure 4: Modified design of HTR-PM for thermal recovery.

one of them is in a dangerous status. In this reference oil field, the number of injected wells at the same time is around $30(20-40)$ and the mass flow rate of water to each well is around $2.31 \mathrm{~kg} / \mathrm{s}$ (200 ton/day). A single reactor of HTR-PM can provide enough injected water since the flow out of the steam generator is $98 \mathrm{~kg} / \mathrm{s}$, around 8600 ton/day.

The process in the modified secondary loop of HTRPM can be described as follows. The water at $75.08 \mathrm{~kg} / \mathrm{s}$ and $25^{\circ} \mathrm{C}$ is driven to the secondary loop by a pump. The water is purified and softened by a water treatment plant mainly consisting of several sand filters and several ion exchangers. The cool water is heated by the superheated steam from the output of the steam generator at a steam jet mixer. Then the water is pumped to a deoxidizer and heated again by the superheated steam at another steam jet mixer. Finally, the water at around $205^{\circ} \mathrm{C}$ and $98 \mathrm{~kg} / \mathrm{s}$, which is same as the original design of HTR-PM, is fed to the once-through helical steam generator. The output water of the steam generator at around $566^{\circ} \mathrm{C}$ is mainly divided in two branches. One fluid is deployed as feedback to the two steam jet mixers and the deoxidizer in order to heat the feed water instead of the conventional electrical heaters. The main fluid at $75.08 \mathrm{~kg} / \mathrm{s}(6500 \mathrm{ton} /$ day $)$ and $566^{\circ} \mathrm{C}$ is provided to the superheated steam injection system for heavy oil thermal recovery.

2.5. Economic Comparison between Steam Injection by Conventional Boiler and HTR-PM. By considering the construction investment, fuel cost, and operating cost, the full cost of the steam injection by burning coal or natural gas can be estimated [18]. The construction investment and operating cost are converted to cost per ton steam injection which are shown in Table 3. The full cost of steam injection by HTR-PM can also be estimated [19]. In the same way, the construction investment and operating cost of steam injection by HTR-PM are converted to cost per ton of steam injection in the same Table. The full cost of steam injection with unit of $\$ / t$ means the total cost for injecting 1 ton of steam.
For the uncertainty evaluation, if the bank rate rises to $10 \%$ and fuel cost decreases by $10 \%$, the costs can be estimated as shown in Table 4.

From these results, it can be found that the steam injection by HTR-PM is still a competitive choice compared to the steam injection by the conventional boiler burning coal or natural gas even with lower fossil fuel price and higher bank rate.

To consider the quality difference of the steam produced by the fossil fuel boiler or HTR-PM, the full cost can be changed to the enthalpy of injected steam instead of the mass of it. The full costs for steam injection by HTR-PM or burning coal or natural gas are shown in Table 5, which shows the cost to provide $1 \mathrm{~kJ}$ enthalpy to the injected steam. According to this table, the steam injection by HTR-PM has an obvious economic advantage on the steam injection by conventional boilers burning coal or natural gas even with lower fossil fuel price and higher bank rate.

\section{Design and Development of GIS with Thermal Hydraulic Analysis Function}

3.1. Need of GIS with Thermal Hydraulic Analysis Function. It is easy to conclude that the concentrative steam supply by HTR has advantages over the conventional dispersed steam supply by boilers at the aspects of labor expenditure $[18,19]$. In addition, it can also be predicted that the superheated steam can beat the wet steam because of higher specific enthalpy and specific volume $[5,6]$. However, some results from actual engineering side are needed for answering the following questions.

(i) Will the quality of the steam by HTR be same as or even worse than the quality of the steam by boiler because of heat loss since the superheated steam has to flow through an extra main steam pipeline which is several kilometers long? If it is, the HTR design for thermal recovery technology will lose its most important strength over conventional technology. 
TABLE 2: Basic configuration of injection.

\begin{tabular}{lc}
\hline & Injection with boiler/HTR-PM \\
\hline Number of used boiler/HTR-PM reactor at same time & $15 / 1$ \\
Number of injected wells at same time & $30(20-40)$ \\
Number of boilers & 100 \\
Number of wells & 6000 \\
Initial temperature of steam $\left({ }^{\circ} \mathrm{C}\right)$ & $318.05 / 566$ \\
Mass flow out of each boiler/HTR-PM (ton/day) & $200-800 / 6500$ \\
Mass flow rate of water to each well (ton/day) & Around 2000 \\
Initial pressure of steam $(\mathrm{MPa})$ & $11 / 14.3$ \\
Initial dryness of steam & $0.725 / 1$ \\
Average length of main steam pipeline (km) & $0 / 7.5$ \\
Area of reference oil field $\left(\mathrm{km}{ }^{2}\right)$ & $20 \times 20$ \\
Average length of branch steam pipeline $(\mathrm{km})$ & 0.8 \\
Average distance from injection station to well head & 0.2 \\
Depth of typical well $(\mathrm{m})$ & 759.75 \\
\hline
\end{tabular}

TABLE 3: Costs of steam injection by boiler and HTR-PM.

\begin{tabular}{lccccc}
\hline $\begin{array}{l}\text { Injection } \\
\text { mode }\end{array}$ & $\begin{array}{c}\text { Construction } \\
\text { investment } \\
(\$ /(t \cdot y))\end{array}$ & $\begin{array}{c}\text { Fuel cost } \\
\left(\$ / t \text { or } \$ / \mathrm{m}^{3}\right)\end{array}$ & $\begin{array}{c}\text { Operating } \\
\text { cost }(\$ / t)\end{array}$ & $\begin{array}{c}\text { Full operating } \\
\text { cost }(\$ / t)\end{array}$ & $\begin{array}{c}\text { Full cost } \\
\text { for steam } \\
\text { injection }(\$ / t)\end{array}$ \\
\hline Coal & 29.78 & 27.99 & 8.766 & 12.04 & 14.69 \\
Natural gas & 15.54 & 0.1541 & 10.45 & 14.50 & 15.88 \\
HTR-PM & 95.17 & - & - & 5.62 & 14.07 \\
\hline
\end{tabular}

Time $=30$ years, bank rate $=8 \%$.

(ii) The thermal hydraulic analysis of a whole actual oil field is rather difficult because the situation is very complex when the injected steam flows through the main pipeline, branch pipeline, steam injecting station, well tube, and so forth. The mass flow rate, temperature, pressure, and dryness of the steam change in a nonlinear manner in the process of the steam transportation, which cannot be simply considered as a process in one typical pipeline.

(iii) Since the superheated steam has higher specific volume than the wet steam, the velocity of flow of the superheated steam will be much higher than that of wet steam if the mass rate of injected steam stays the same. Is the pressure drop acceptable or not before the steam flows to oil reservoirs through the extended pipeline?

(iv) Should the main steam pipeline be placed overground or underground? Can the superheated steam injection fit for all kinds of well structures?

A GIS with thermal hydraulic analysis function can play the role to answer the above questions. The GIS can serve the following functions.

(i) Management of geographic information of an oil field such as coordinates of HTR-PM, boiler, pipeline, steam injecting station, and reservoir. (ii) Management of configuration information of HTRPM, boiler, pipeline, and reservoir including pressure, temperature, mass flow rate of output steam of HTR-PM or boiler, geometrical and thermodynamics characteristics of pipeline and reservoir, and so forth.

(iii) Calculation of loss of heat, change of pressure, and possible phase change when the steam flows from HTR-PM or boiler to reservoir.

3.2. Structure and Function of The GIS. The structure and function of the GIS are shown in Figure 5. The GIS with thermal hydraulic analysis function is developed based on component-based development where the third-party developed GIS component is embedded in it. It mainly consists of three modules.

(i) The thermal-hydraulic calculation module can simulate the change of thermal-hydraulic status of the steam from HTR or boiler to oil reservoirs. It can access the information of each geographic symbol in the GIS through temporary input/output file. In the GIS, the geographic symbols represent HTR-PM and various components of the oil field such as boiler, pipeline, steam injecting station, reservoir, and so forth. The thermal-hydraulic calculation module will be explained in Section 4. 
TABLE 4: Costs of steam injection at lower fossil fuel price and higher bank rate.

\begin{tabular}{lccccc}
\hline $\begin{array}{l}\text { Injection } \\
\text { mode }\end{array}$ & $\begin{array}{c}\text { Construction } \\
\text { investment } \\
(\$ /(t \cdot y))\end{array}$ & $\begin{array}{c}\text { Fuel cost } \\
\left(\$ / t \text { or } \$ / \mathrm{m}^{3}\right)\end{array}$ & $\begin{array}{c}\text { Operating } \\
\text { cost }(\$ / t)\end{array}$ & $\begin{array}{c}\text { Full operating } \\
\text { cost }(\$ / t)\end{array}$ & $\begin{array}{c}\text { Full cost for steam } \\
\text { injection }(\$ / t)\end{array}$ \\
\hline Coal & 29.78 & 25.19 & 8.766 & 11.71 & 14.87 \\
Natural gas & 15.54 & 0.1368 & 10.45 & 14.10 & 15.74 \\
HTR-PM & 95.17 & - & - & 5.62 & 15.72 \\
\hline
\end{tabular}

Time $=30$ years, bank rate $=10 \%$.

TABLE 5: Costs of steam injection by considering enthalpy difference of steam.

\begin{tabular}{lcc}
\hline $\begin{array}{l}\text { Injection } \\
\text { mode }\end{array}$ & $\begin{array}{c}\text { Full cost for steam } \\
\text { injection } \\
(\text { mills/kJ) }\end{array}$ & $\begin{array}{c}\text { Full cost for steam } \\
\text { injection under higher } \\
\text { bank rate and lower } \\
\text { fossil fuel price } \\
\text { (mills/kJ) }\end{array}$ \\
\hline Coal & 0.00621 & 0.00629 \\
Natural gas & 0.00672 & 0.00666 \\
HTR-PM & 0.00402 & 0.00449 \\
\hline
\end{tabular}

Time $=30$ years, higher bank rate $=10 \%$, lower fossil fuel price $=90 \%$ of normal price.

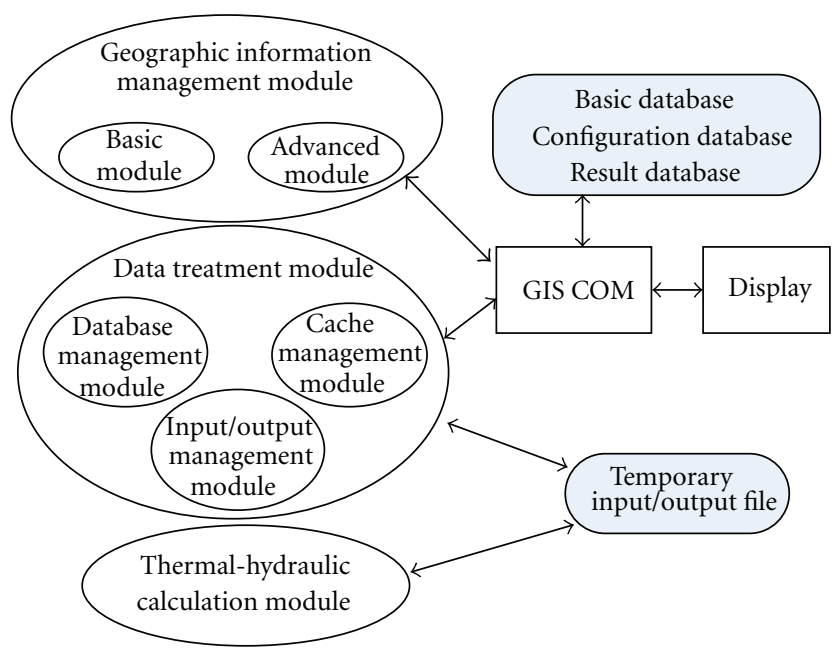

FIGURE 5: Structure and function of the GIS.

(ii) The data treatment module includes three submodules: database management module, cache management module, and input/output management module. The database management module can access the basic database, the configuration database, and the result database. The basic database stores the basic information of various geographic symbols in the GIS including name, ID, type, geometry, and so forth. The configuration database stores the information for the thermal hydraulic analysis such as inner diameter of pipeline, outside diameter pipeline, type of pipeline, type of well, heat conductivity of heat-insulating material, and so forth. The result database can save the thermal hydraulic analysis result of each symbol in the GIS. The input/output management module mainly reads and writes the temporary input/output files to provide data to the thermal-hydraulic calculation module and get results from the thermal hydraulic analysis. The cache treatment module gets the information from the database and provides it to the geographic information management module for finding the flow route of the steam out of the HTR or boiler.

(iii) The Geographic Information Management module can realize some basic management functions and advanced management function through the GIS component. The basic management functions can perform the zoom in, zoom out, move, centralize, and other functions for management of the geographic symbol. The advanced management function can determine the flow route of the steam out of the HTR or boiler according to the configuration of each symbol.

3.3. How the GIS Works. The flow chart of the GIS is shown in Figure 6. Firstly, the GIS will load the geographic information and configuration information from the basic and configuration databases. Then, the user can modify the configuration information of the geographic symbol by selecting the corresponding symbol through the GIS interface.

After the process of configuration, the flow route from the HTR or boiler to oil reservoirs will be determined according to the configuration since sometime dozens of oil wells out of thousand existing wells in the oil field will be selected for steam injection. The output of the boiler or HTR, such as temperature, pressure, and mass flow rate of steam, will be obtained. Then, the thermal hydraulic analysis will be carried out when the steam flows in the pipeline and diverging points before the Steam Injecting Station (SIS). After the treatment of flow at SIS, the thermal-hydraulic behavior of the flow in the pipeline and the oil well will be calculated. Finally, all the above results will be recorded for display and analysis.

Figure 7 shows the snapshot when the GIS works for thermal hydraulic analysis.

\section{Thermal-Hydraulic Models for GIS}

4.1. Basic Model and Its Treatment. The whole flow route after the HTR or boiler consists of main steam pipeline, 


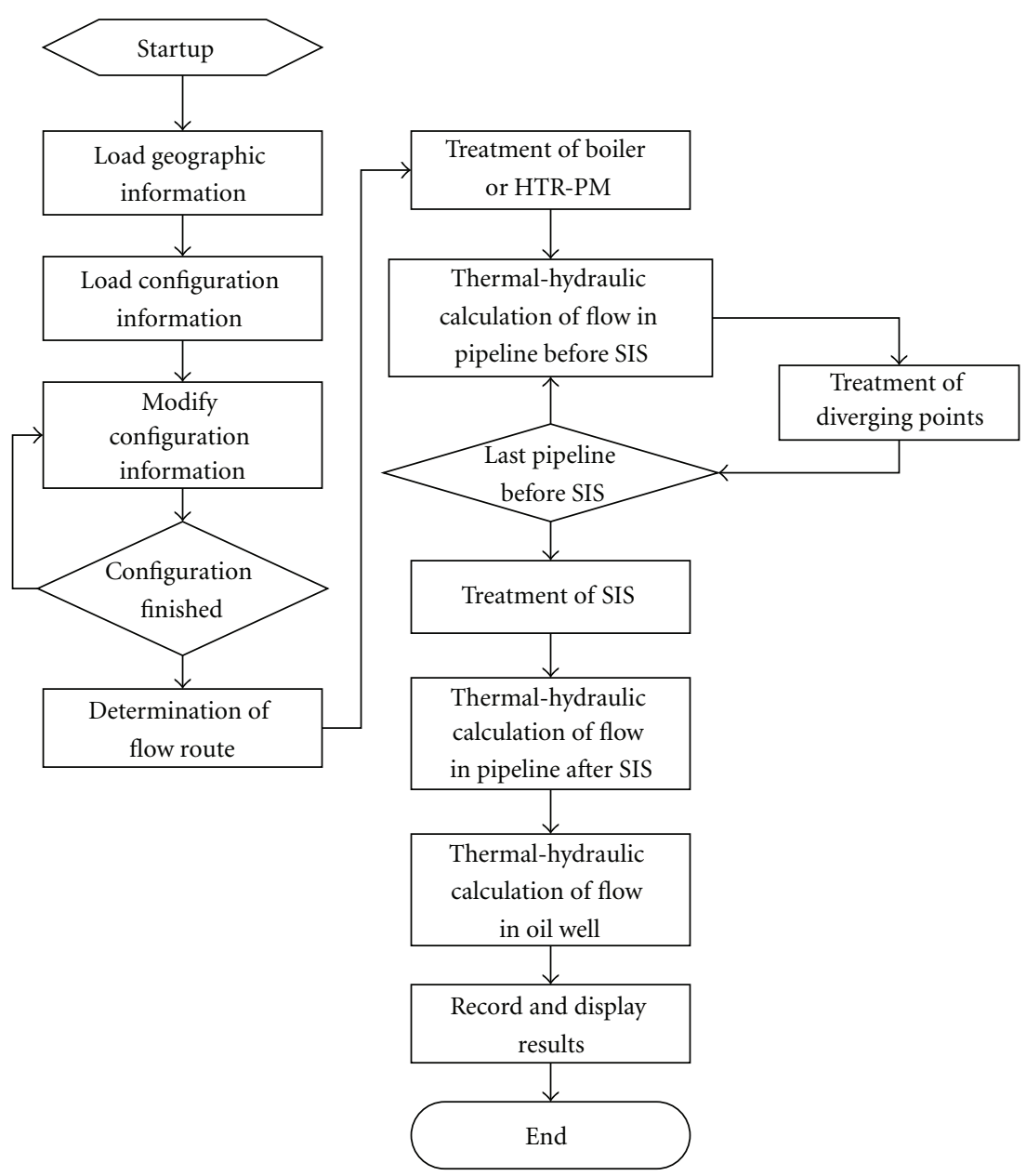

FIGURE 6: Flow chart of the GIS.

diverging point, branch steam pipeline, SIS, and oil well tube. The change of pressure, temperature, and flow rate occurs when the steam flows through the flow route. As boundary conditions, the pressure, temperature (dryness for wet steam), and mass flow rate of the steam are fixed at the outlet of the HTR steam generator or boiler.

When analyzing the thermal-hydraulic behavior of the steam flow in the pipeline and well tube, some basic assumptions are adopted.

(i) The pressure and flow rate of the steam are analyzed based on quasi-steady state model.

(ii) Steam is compressible and treated as a continuum medium.

According to the assumptions mentioned above, some governing equations can be formulated as follows.

(i) Mass conservation

$$
\frac{u}{v}=\text { const. }
$$

(ii) Momentum conservation

$$
g \sin \theta d L+u d u+\frac{d P}{\rho}=-\lambda \frac{u^{2}}{2} \frac{d L}{D_{i}} .
$$

(iii) Energy conservation

$$
d Q=g \sin \theta d L+d h+u d u .
$$

In (4)-(6), $u$ is the flow speed of steam or water; $v$ is the specific volume of steam or water; $\rho$ is the density of steam or water; $P$ is the pressure of steam or water; $L$ is the length of the steam or water flow; $\lambda$ is the friction resistance coefficient of the pipeline or well tube; $D_{i}$ is the equivalent diameter of the pipeline or well tube; $g$ is the acceleration of gravity; $\theta$ is the angle between the flow and the horizontal direction; $d Q$ is the heat absorbed per unit mass of steam or water; $h$ is the specific enthalpy of the steam or water.

$\lambda$ can be calculated as follows [20]:

$$
\lambda=\frac{64}{\operatorname{Re}} \quad(\operatorname{Re}<2300)
$$$$
\lambda=\frac{0.316}{\operatorname{Re}^{0.25}} \quad\left(2300 \leq \operatorname{Re}<80 \frac{D_{i}}{\Delta_{d}}, \operatorname{Re}<8 \times 10^{4}\right)
$$ 




FIGURE 7: Snapshot of the GIS.

$$
\begin{gathered}
\frac{1}{\sqrt{\lambda}}=2 \lg (\operatorname{Re} \sqrt{\lambda})-0.8 \\
\left(2300 \leq \operatorname{Re}<80 \frac{D_{i}}{\Delta_{d}}, \operatorname{Re} \geq 8 \times 10^{4}\right) \\
\frac{1}{\sqrt{\lambda}}=-2 \lg \left(\frac{\Delta_{d}}{3.7 D_{i}}+\frac{2.51}{\operatorname{Re} \sqrt{\lambda}}\right) \\
\left(80 \frac{D_{i}}{\Delta_{d}} \leq \operatorname{Re}<4160\left(\frac{D_{i}}{2 \Delta_{d}}\right)^{0.85}\right) \\
\lambda=\left(2 \lg \left(\frac{D_{i}}{2 \Delta_{d}}\right)+1.74\right)^{-2}\left(\operatorname{Re} \geq 4160\left(\frac{D_{i}}{2 \Delta_{d}}\right)^{0.85}\right),
\end{gathered}
$$

where Re is the Reynolds number; $\Delta_{d}$ is roughness of tube wall.

In the three conservation equations (4)-(6) in this model, the independent variables are pressure $P$ and temperature $T$ (dryness $x$ for wet steam). The related differential equations are described by

$$
\begin{array}{lll}
\frac{d P}{d L}=f_{1}(P, T) & \text { or } & \frac{d P}{d L}=f_{1}^{\prime}(P, x) \\
\frac{d T}{d L}=f_{2}(P, T) & \text { or } & \frac{d x}{d L}=f_{2}^{\prime}(P, x) .
\end{array}
$$

In order to get the above two equations, from the three conservation equations, the following expression of enthalpy and specific volume are employed:

$$
\begin{array}{ccc}
\frac{d h}{d L}=\frac{\partial h}{\partial P} \frac{d P}{d L}+\frac{\partial h}{\partial T} \frac{d T}{d L} & \text { or } \quad \frac{d h}{d L}=\frac{\partial h}{\partial P} \frac{d P}{d L}+\frac{\partial h}{\partial x} \frac{d x}{d L} \\
\frac{d v}{d L}=\frac{\partial v}{\partial P} \frac{d P}{d L}+\frac{\partial v}{\partial T} \frac{d T}{d L} & \text { or } \quad \frac{d v}{d L}=\frac{\partial v}{\partial P} \frac{d P}{d L}+\frac{\partial v}{\partial x} \frac{d x}{d L} .
\end{array}
$$

From (4), (5), (6), (9), and (10), (11) and (12) are deduced for superheated steam or water (use $x$ instead of $T$ for wet steam) as follows:

$$
\begin{gathered}
\frac{d P}{d L}=\frac{B F+C E}{A E-B D} \\
\frac{d T}{d L}=\frac{A F+C E}{B D-A E} \quad \text { or } \quad \frac{d x}{d L}=\frac{A F+C E}{B D-A E}
\end{gathered}
$$

where

$$
\begin{gathered}
A=v+\frac{u^{2}}{v} \frac{\partial v}{\partial P} \\
B=\frac{u^{2}}{v} \frac{\partial v}{\partial T} \quad \text { or } \quad B=\frac{u^{2}}{v} \frac{\partial v}{\partial x}, \\
C=g \sin \theta+\lambda \frac{u^{2}}{2 D_{i}}, \\
D=\frac{\partial h}{\partial P}+\frac{u^{2}}{v} \frac{\partial v}{\partial P}, \\
\frac{\partial h}{v} \frac{\partial v}{\partial T} \quad \text { or } \quad E=\frac{\partial h}{\partial x}+\frac{u^{2}}{v} \frac{\partial v}{\partial x} \\
F=\frac{d Q}{d L}-g \sin \theta
\end{gathered}
$$


Equations (11) and (12) are numerically solved by using a variable step four-order explicit Runge-Kutta method $[21,22]$. For the superheated steam or water, the iteration equation (for the wet steam, use $x$ instead of $T$ ) can be expressed as follows:

$$
\begin{gathered}
P^{\prime}=P_{0}+\frac{l}{6}\left(K_{11}+2 K_{21}+2 K_{31}+K_{41}\right), \\
T^{\prime}=T_{0}+\frac{l}{6}\left(K_{12}+2 K_{22}+2 K_{32}+K_{42}\right), \\
K_{11}=\left.\frac{d P}{d L}\right|_{P=P_{0}, T=T_{0}}, \\
K_{12}=\left.\frac{d T}{d L}\right|_{P=P_{0}, T=T_{0}}, \\
K_{21}=\left.\frac{d P}{d L}\right|_{P=P_{0}+(l / 2) K_{11}, T=T_{0}+(l / 2) K_{12}}, \\
K_{22}=\left.\frac{d T}{d L}\right|_{P=P_{0}+(l / 2) K_{11}, T=T_{0}+(l / 2) K_{12}}, \\
K_{31}=\left.\frac{d P}{d L}\right|_{P=P_{0}+(l / 2) K_{21}, T=T_{0}+(l / 2) K_{22}}, \\
K_{32}=\left.\frac{d T}{d L}\right|_{P=P_{0}+(l / 2) K_{21}, T=T_{0}+(l / 2) K_{22}}, \\
K_{41}=\left.\frac{d P}{d L}\right|_{P=P_{0}+(l / 2) K_{31}, T=T_{0}+(l / 2) K_{32}}, \\
K_{42}=\left.\frac{d T}{d L}\right|_{P=P_{0}+(l / 2) K_{31}, T=T_{0}+(l / 2) K_{32}},
\end{gathered}
$$

where $l$ is the iteration length of $L ; P_{0}$ and $T_{0}$ are the value of the previous iteration step.

4.2. Calculation of Heat Loss. The structure of overground or underground pipeline is shown in Figure 8. The structure of the heat insulation oil well tube is shown in Figure 9. There is a packer at the bottom of the whole well tube near the oil layer which is used to seal the cavity inside the sleeve. With the packer, the cavity will be filled with air only. Otherwise, water will occupy a partial height of the cavity. Different from the heat insulation well tube, the normal well tube does not have the heat barrier material and the thermal sleeve of Figure 9.

When solving the equations mentioned in Section 4.1, the heat absorbed by the pipeline wall and the well tube wall should be obtained [23].

For the case of heat which is lost from the steam or water through the overground pipeline wall to the atmosphere as follows:

$$
d Q_{o}=2 \pi R_{o 4} \times U_{o}\left(T_{f}-T_{a}\right) d L,
$$

where $R_{o 4}$ is the outer radius of the thermal sleeve; $U_{o}$ is the equivalent coefficient of heat transfer; $T_{f}$ is the temperature of steam or water fluid; $T_{a}$ is the temperature of atmosphere next to the thermal sleeve.

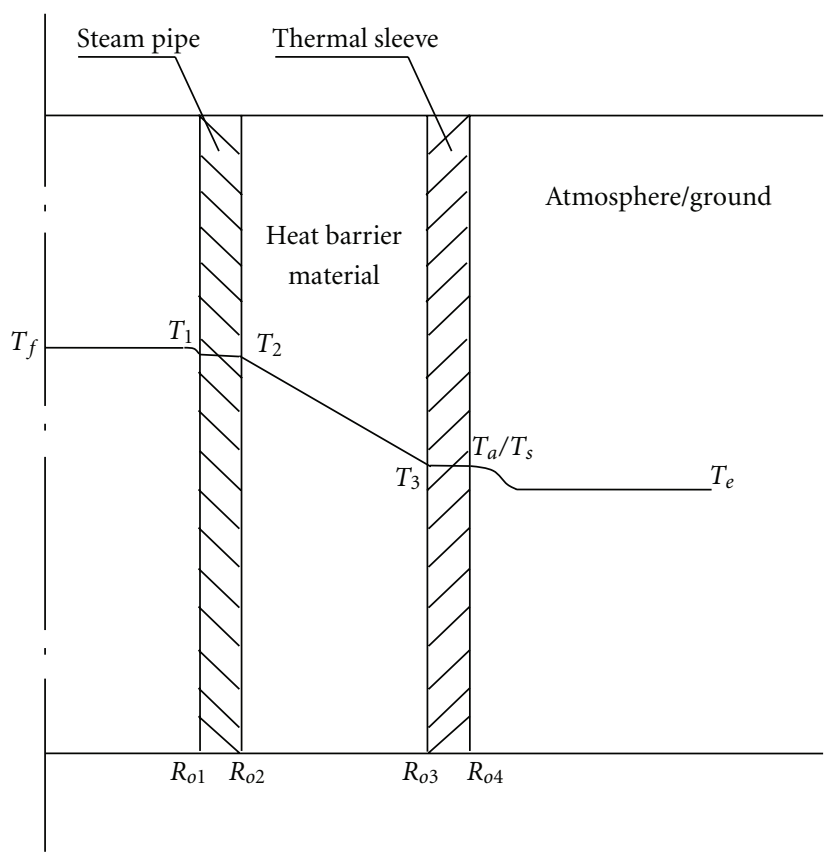

FIGURE 8: Structure of overground or underground pipeline.

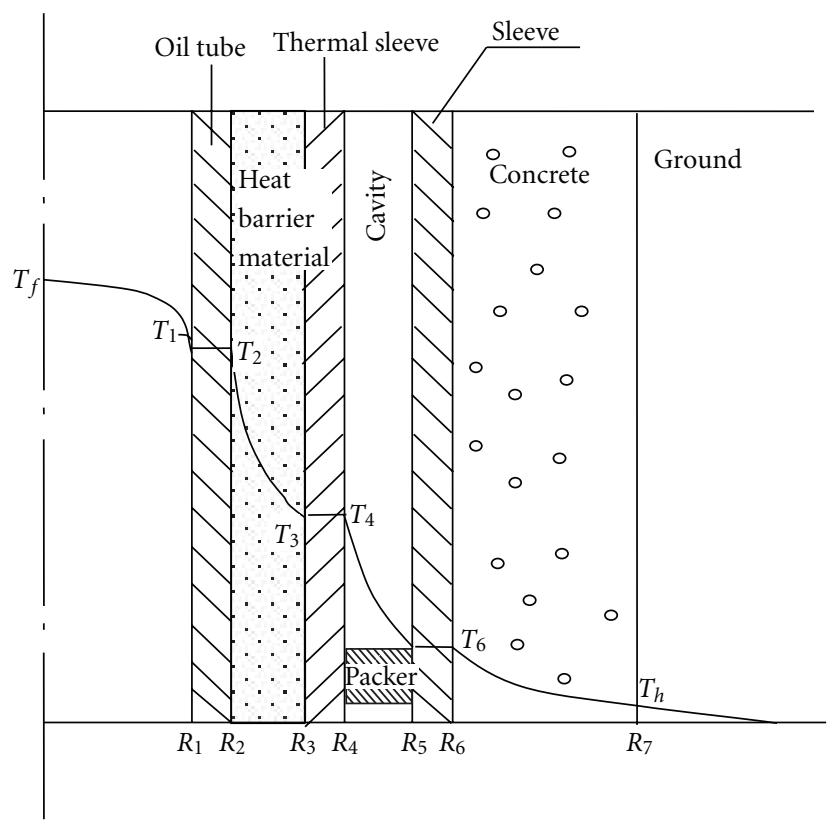

FIGURE 9: Structure of insulation oil well tube.

$U_{o}$ can be described as follows, in which the thermal resistance of convective heat transfer between steam/water and pipe and the thermal resistance of steam pipe and thermal sleeve are ignored:

$$
U_{o}=\left[\frac{R_{o 4} \ln \left(R_{o 3} / R_{o 2}\right)}{\lambda_{\text {ins } 0}}+\frac{1}{h_{c 0}}\right]^{-1},
$$

where $R_{02}$ is the outer radius of the steam pipe; $R_{03}$ is the inner radius of the thermal sleeve; $\lambda_{\text {inso } 0}$ is the coefficient of thermal conductivity of the heat barrier material; $h_{c 0}$ is 
the coefficient of convective heat transfer of air out of the thermal sleeve.

For the case of heat which is lost from the steam or water through the underground pipeline wall to the earth

$$
d Q_{u}=2 \pi R_{o 4} \times U_{u}\left(T_{f}-T_{s}\right) d L,
$$

where $U_{u}$ is the equivalent coefficient of heat transfer; $T_{s}$ is the temperature of soil next to the thermal sleeve.

$U_{u}$ can be described as follows:

$$
U_{u}=\left[\frac{R_{o 4} \ln \left(R_{o 3} / R_{o 2}\right)}{\lambda_{\text {ins } 0}}\right]^{-1} .
$$

For the case of heat which is lost from steam or water through the oil well tube wall to the earth

$$
d Q_{t}=2 \pi R_{7} \times U_{t}\left(T_{f}-T_{h}\right) d L,
$$

where $R_{7}$ is the outer diameter of the concrete; $U_{t}$ is the equivalent coefficient of heat transfer; $T_{h}$ is the temperature of soil next to the concrete.

$U_{t}$ can be described as the following kinds of situation in which the thermal resistance of convective heat transfer between steam/water and pipe and the thermal resistance of the steam pipe, thermal sleeve and sleeve are ignored.

(i) Heat insulation tube with packer

$$
U_{t}=\left[\frac{R_{7}}{R_{2} U_{\mathrm{ins}}}+\frac{R_{7}}{R_{4}\left(h_{c}+h_{r}\right)}+\frac{R_{7} \ln \left(R_{7} / R_{6}\right)}{\lambda_{\mathrm{cem}}}\right]^{-1} .
$$

(ii) Heat insulation tube without packer

When the cavity is filled with air, it is the same as (20).

When the cavity is filled with water as follows:

$$
U_{t}=\left[\frac{R_{7}}{R_{2} U_{\text {ins }}}+\frac{R_{7}}{R_{4} h_{c}}+\frac{R_{7} \ln \left(R_{7} / R_{6}\right)}{\lambda_{\text {cem }}}\right]^{-1} .
$$

(i) Normal tube with packer

$$
U_{t}=\left[\frac{R_{7}}{R_{4}\left(h_{c}+h_{r}\right)}+\frac{R_{7} \ln \left(R_{7} / R_{6}\right)}{\lambda_{\text {cem }}}\right]^{-1} .
$$

(ii) Normal tube without packer

When the cavity is filled with air, it is the same as (22).

When the cavity is filled with water as follows:

$$
U_{t}=\left[\frac{R_{7}}{R_{4} h_{c}}+\frac{R_{7} \ln \left(R_{7} / R_{6}\right)}{\lambda_{\text {cem }}}\right]^{-1},
$$

where $R_{2}, R_{4}, R_{6}$, and $R_{7}$ are the outer radius of oil tube, outer radius of the thermal sleeve, outer radius of the sleeve, and outer radius of concrete, respectively; $U_{\text {ins }}$ is the equivalent coefficient of heat transfer of the heat insulation tube; $h_{c}$ is the equivalent coefficient of conductive and convective heat transfer in the cavity; $h_{r}$ is the coefficient of radiation heat transfer in the cavity; $\lambda_{\text {cem }}$ is the coefficient of conductive heat transfer of the concrete.
4.3. Calculation of Local Pressure Change. For the case of superheated steam or water, the local pressure change can be described as follows:

$$
\Delta p=\lambda_{l} \frac{u_{d}^{2}}{2 v},
$$

where $\lambda_{l}$ is the equivalent local resistance coefficient; $u_{d}$ is the average flow rate of downstream steam or water.

The value of $\lambda_{l}$ can be divided as the four following situations which are shown in Table 6 [20].

For the case of wet steam, $\Delta p$ can be obtained by treating the wet steam as the single phase mentioned above. Then, the local pressure change will be corrected as follows [20].

$$
\Delta p_{s}=\Delta p\left(1+\frac{B}{X}+\frac{1}{X^{2}}\right)
$$

where

$$
\begin{gathered}
X=\left(\frac{1-x}{x}\right)^{0.9} \cdot\left(\frac{v^{\prime}}{v^{\prime \prime}}\right)^{0.5} \cdot\left(\frac{\mu^{\prime}}{\mu^{\prime \prime}}\right)^{0.1}, \\
B=B_{1} \cdot\left(\sqrt{\frac{v^{\prime \prime}}{v^{\prime}}}+\sqrt{\frac{v^{\prime}}{v^{\prime \prime}}}\right),
\end{gathered}
$$

where $v^{\prime}$ is the specific volume of saturated water; $v^{\prime \prime}$ is the specific volume of saturated steam; $\mu^{\prime}$ is the dynamic viscosity coefficient of saturated water; $\mu^{\prime \prime}$ is the dynamic viscosity coefficient of saturated steam.

The value of $B_{1}$ can be divided as the four following situations which are shown in Table 7.

\section{Thermal Hydraulic Analysis for Thermal Re-covery}

5.1. Basic Configuration. Table 8 shows the basic parameters and their values of the main steam pipeline and branch steam pipeline. There are four kinds of branch steam pipeline with different inner diameter and thickness according to their mass flow rate. According to the study, the thermal conductivity of heat barrier material is changed with the temperature of fluid [24]. When the temperature of the fluid is higher than $400^{\circ} \mathrm{C}$, a linear relation is adopted in which the thermal conductivity will be increased with the rise of temperature of the fluid. Otherwise, the thermal conductivity is set as a constant. The thermal conductivity of the main steam pipeline is less than that of the branch steam pipeline.

Table 9 shows the basic parameters and their values of oil well. Here, the values of basic parameters of all oil wells are set as the same value in order to compare the difference of heat loss, pressure change, and possible phase transformation of different designs. Actually, the values of basic parameters of different oil wells may be different to each other, such as height of well, roughness of well tube, and so forth. The effect of the joint is considered which will increase the heat loss when the well tube is the heat insulation tube.

Table 10 shows the basic parameters and their values of environment. 
TABLE 6: Values of $\lambda_{l}$ in the case of steam or water.

\begin{tabular}{|c|c|c|}
\hline \multicolumn{2}{|l|}{ Situation } & Value \\
\hline \multicolumn{2}{|l|}{ Sudden enlargement pipe or tube } & $\begin{array}{l}\lambda_{l}=\left(\frac{A_{2}}{A_{1}}-1\right)^{2} \\
\text { where } A_{1} \text { is the sectional area of upstream flow channel; }\end{array}$ \\
\hline \multicolumn{2}{|l|}{ Sudden contraction pipe or tube } & $\begin{array}{l}A_{2} \text { is the sectional area of downstream flow channel. } \\
\lambda_{l}=0.5\left(1-\frac{A_{2}}{A_{1}}\right)\end{array}$ \\
\hline \multirow[t]{2}{*}{$90^{\circ}$ bend } & & $\lambda_{l}=0.12$ \\
\hline & Gate valve & $\lambda_{l}=0.2$ \\
\hline \multirow[t]{2}{*}{ Valve } & Ball valve & $\lambda_{l}=10.0$ \\
\hline & Control valve & $\lambda_{l}=5.0$ \\
\hline
\end{tabular}

TABLE 7: Values of $B_{1}$ in the case of wet steam.

\begin{tabular}{|c|c|c|}
\hline Situation & & Value \\
\hline Sudden enlargement pipe or tube & & $B_{1}=1.0$ \\
\hline Sudden contraction pipe or tube & & $B_{1}=1.0$ \\
\hline $90^{\circ}$ bend & & $\begin{array}{l}B_{1}=1+35 \frac{D_{i}}{l} \\
\text { where } l \text { is the } \\
\text { length of the bend }\end{array}$ \\
\hline \multirow{3}{*}{ Valve } & Gate valve & $B_{1}=1.5$ \\
\hline & Ball valve & $B_{1}=2.3$ \\
\hline & Control valve & $B_{1}=1.0$ \\
\hline
\end{tabular}

5.2. Introduction of Result. The GIS embedded with thermal hydraulic analysis function is applied to analyze the thermal hydraulic process in the reference heavy oil field whose basic configuration is mentioned above. The heat loss, pressure change, and possible phase transformation are calculated and analyzed when the steam flows through the pipeline and is injected into oil reservoirs.

Table 11 shows the different scenarios and its serial number. Two kinds of injection are considered: wet steam injection by boiler and superheated steam injection by HTRPM. Two kinds of pipeline are considered: overground and underground. Four kinds of oil reservoir structure are included: heat insulation tube with packer, heat insulation tube without packer, normal tube with packer, and normal tube without packer.

Figure 10 shows the heat exchange of the 16 scenarios at different stages when the steam flows out of HTR-PM or boilers to oil reservoirs. The loss of heat is an average value since 30 oil wells are selected for injection and the loss of heat will be different when the steam flows to different oil wells. For the first 8 scenarios where superheated steam is provided by HTR-PM, the enthalpy of the fluid out of HTR$\mathrm{PM}$ is around $3500 \mathrm{~kJ} / \mathrm{kg}$. After flowing through the main steam pipeline, the enthalpy of the fluid before entering the steam line goes down to $2800-2900 \mathrm{~kJ} / \mathrm{kg}$. Because of the loss of heat in the branch steam pipeline, the enthalpy of the fluid before the well head becomes less than $2800 \mathrm{~kJ} / \mathrm{kg}$. The heat loss in the well tube is determined by the structure of the well, where the biggest loss occurs in the normal tube

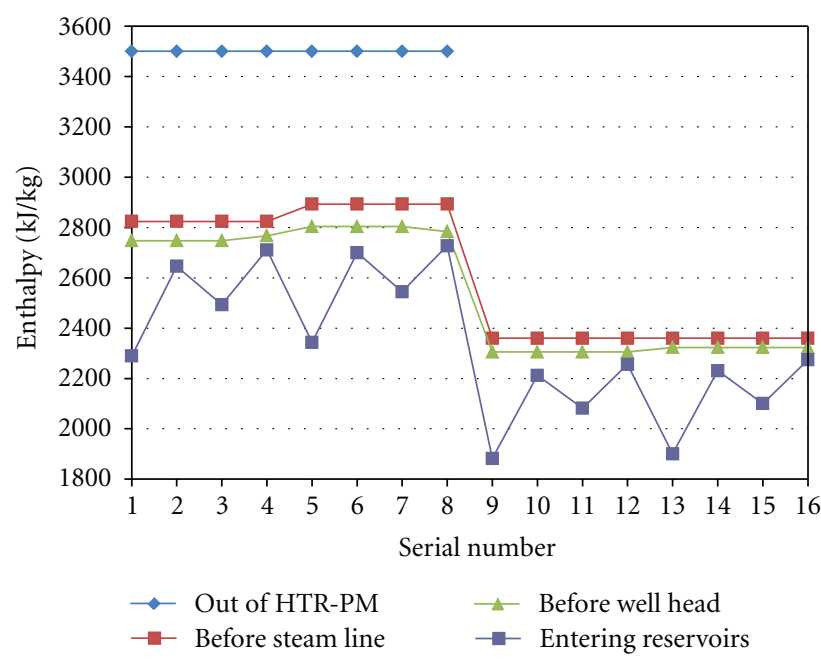

Figure 10: Heat of steam at different stages in the 16 scenarios.

without packer and the smallest loss in the heat insulation tube with packer. For the other 8 scenarios where the wet steam is provided by boiler, the enthalpy of the fluid out of boilers is less than $2400 \mathrm{~kJ} / \mathrm{kg}$. Since the fluid from the boiler does not flow through the main steam pipeline but directly flows into the branch steam pipeline, there are only three stages for the fluid provided by boiler. The features of heat loss of the fluid in the last 8 scenarios are the same as the first 8 scenarios.

Figure 11 shows the dryness of the fluid entering the oil reservoirs and the pressure change of the fluid after the steam flows through the main steam pipeline, the branch steam pipeline, and the well tube. The dryness and the pressure change are also average values since their values will be different when the steam flows to the 30 different oil wells. The dryness of the fluid entering reservoirs of scenarios 18 is much higher than that of scenarios 9-16. Especially for scenarios 2, 4, 6, 8 where the heat insulation tube is used, almost all oil reservoirs are injected by superheated steam (29 out of 30 wells). The pressure change of fluid of scenarios 18 is much higher than that of scenarios 9-16 since the fluid out of HTR-PM have to flow through an extra main steam pipeline which is several kilometers long. 
TABLE 8: Basic parameters of pipeline.

\begin{tabular}{ll}
\hline Parameter & Value \\
\hline Roughness $(\mathrm{mm})$ & 0.014 \\
Inner diameter $(\mathrm{m})$ & $0.4 / 0.3 / 0.2 / 0.1$ \\
Thickness $(\mathrm{mm})$ & $15 / 15 / 8 / 7$ \\
Thermal conductivity coefficient of heat & $0.058+t \times 0.9 E-4\left(t>400^{\circ} \mathrm{C}\right)$ \\
barrier material $(\mathrm{J} /(\mathrm{m} \cdot \mathrm{s} \cdot \mathrm{K}))$ & $0.094 / 0.125\left(t \leq 400^{\circ} \mathrm{C}\right)$ \\
Thickness of heat barrier material $(\mathrm{m})$ & 0.13 \\
Horizontal angle $\left({ }^{\circ}\right)$ & 0 \\
Position & Overground/underground \\
Height of bracket $(\mathrm{m})$ & $0.6 / 0.3$ \\
Cross-sectional area of bracket in thermal & 0.004 \\
sleeve $\left(\mathrm{m}^{2}\right)$ &
\end{tabular}

TABLE 9: Basic parameters of oil well.

\begin{tabular}{lc}
\hline Parameter & Value \\
\hline Roughness of well tube $(\mathrm{mm})$ & 0.014 \\
Inner diameter of well tube $(\mathrm{mm})$ & 62 \\
Outer diameter of well tube $(\mathrm{mm})$ & 73 \\
Thermal conductivity coefficient of heat barrier material $(\mathrm{J} /(\mathrm{m} \cdot \mathrm{s} \cdot \mathrm{K}))$ & $0.0443+t \times 1.39 E-4$ \\
Thickness of thermal sleeve $(\mathrm{mm})$ & 19.5 \\
Inner blackness of cavity & 0.9 \\
Outer blackness of cavity & 0.56 \\
Inner diameter of sleeve $(\mathrm{mm})$ & 224.4 \\
Outer diameter of sleeve $(\mathrm{mm})$ & 324.4 \\
Thickness of concrete $(\mathrm{mm})$ & 30 \\
Thermal conductivity coefficient of concrete $(\mathrm{J} /(\mathrm{m} \cdot \mathrm{s} \cdot \mathrm{K}))$ & 0.516 \\
Length of each well tube $(\mathrm{m})$ & 10 \\
Length of each joint $(\mathrm{m})$ & 0.13 \\
Inner diameter of joint $(\mathrm{mm})$ & 60 \\
Outer diameter of joint $(\mathrm{mm})$ & 76 \\
Height of well $(\mathrm{m})$ & 759.75 \\
\hline
\end{tabular}

TABle 10: Parameter of environment.

\begin{tabular}{lc}
\hline Parameter & Value \\
\hline Tundra exists & NO \\
Temperature of atmosphere and earth surface $\left({ }^{\circ} \mathrm{C}\right)$ & 20 \\
$\begin{array}{l}\text { Starting temperature of zone of constant } \\
\text { temperature }\left({ }^{\circ} \mathrm{C}\right)\end{array}$ & 15 \\
$\begin{array}{l}\text { Starting depth of zone of constant temperature }(\mathrm{m}) \\
\text { Temperature gradient of zone of constant }\end{array}$ & 30 \\
temperature $\left({ }^{\circ} \mathrm{C} / \mathrm{m}\right)$ & 0.018 \\
$\begin{array}{l}\text { Wind speed of earth surface }(\mathrm{m} / \mathrm{s}) \\
\text { Thermal conductivity of soil except tundra } \\
(\mathrm{J} /(\mathrm{m} \cdot \mathrm{s} \cdot \mathrm{K}))\end{array}$ & 2 \\
Thermal diffusivity of soil except tundra $\left(\mathrm{m}^{2} / \mathrm{s}\right)$ & 2.6528 \\
\hline
\end{tabular}

\subsection{Discussion}

(i) For all 8 scenarios where the steam is provided by HTR-PM, the majority of the heat loss exists in the main steam pipeline since it is usually several kilometers long. Another reason is that the temperature of the fluid in the main steam pipeline is relatively higher than the temperature of the fluid in other stages, such in the branch steam pipeline and well tube.

(ii) The heat loss of the fluid in scenarios $1-8$ is much higher than that in scenarios 9-16. However, the heat of fluid entering the oil reservoirs in scenarios $1-8$ is much higher than that in scenarios 9-16.

(iii) In scenarios 5-8 and 13-16 where the pipeline is underground, the heat loss is less than that in scenarios 1-4 and 9-12 when the pipeline is overground. However, the difference between them is small. It shows that the underground pipeline has no obvious advantage on heat insulation over the overground pipeline under the present condition.

(iv) From well head to oil reservoirs, the heat loss in the heat insulated well tube is much lower than that in normal tube.

(v) The dryness of the fluid entering the oil reservoirs in scenarios $1-8$ is much higher than that in scenarios 9-16. Especially in scenarios 2, 4, 6, and 8 where 
TABLE 11: Different scenarios and their serial numbers.

\begin{tabular}{lcccc}
\hline & $\begin{array}{c}\text { HTR/PM } \\
\text { overground }\end{array}$ & HTR-PM/underground & Boiler/overground & Boiler/underground \\
\hline Normal tube without packer & 1 & 5 & 9 & 13 \\
Heat insulation tube without packer & 2 & 6 & 10 & 14 \\
Normal tube with packer & 3 & 7 & 11 & 15 \\
Heat insulation tube with packer & 4 & 8 & 12 & 16 \\
\hline
\end{tabular}

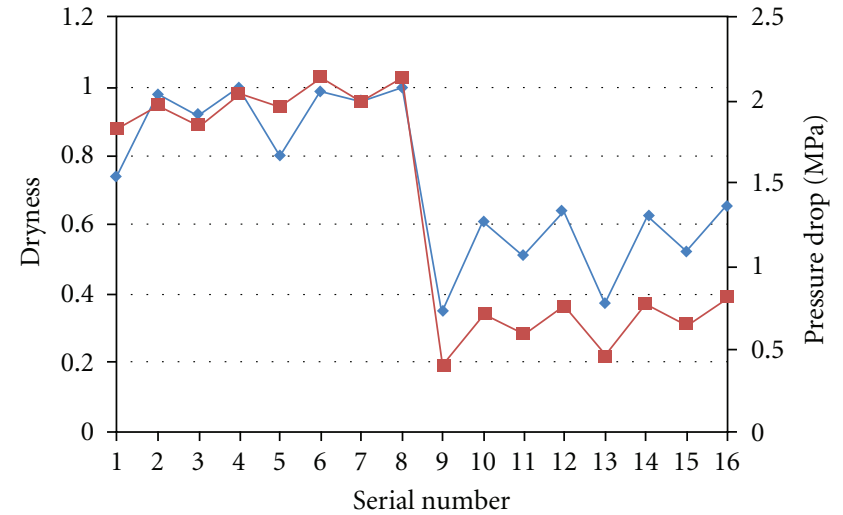

$\longrightarrow$ Dryness entering reservoirs

$\rightarrow|\Delta P|$

Figure 11: Dryness and pressure drop of injected steam in the 16 scenarios.

the insulation well tube is used, the fluid entering the majority of 30 oil reservoirs is superheated steam.

(vi) In scenarios 1-8 where steam is provided by HTR$\mathrm{PM}$, the total flow resistance is much higher than that in scenarios 9-16 where the steam is provided by boiler. The main reason is that the fluid out of HTRPM has to flow through an extra main steam pipeline which is several kilometers long. Another reason is that the specific volume of the fluid in scenarios 1-8 is relatively higher than that in scenarios 9-16.

\section{Conclusions}

In this paper, the strategy of superheated steam injection with a modified design of the secondary loop of HTR-PM is proposed for thermal recovery of heavy oil. A GIS embedded with thermal hydraulic analysis function is developed to analyze the thermal hydraulic parameters of this strategy. The present design of one single reactor of the HTR-PM can fit the need of thermal recovery of the reference oil field where around 20-40 oil wells out of several thousand wells are injected with steam at the same time. Of course, the number of reactors can be changed according to the steam requirements of other oil fields. Thermal hydraulic analysis on two kinds of pipelines and four kinds of well tubes in the reference heavy oil field shows that the strategy is applicable and promising (i) Thermal recovery by HTR-PM is superior to that by conventional boilers since the heat and dryness of the fluid entering the oil reservoirs is much higher than that provided by conventional boilers, which can improve the quality of steam stimulation for heavy oil recovery.

(ii) The location of main pipeline (overground or underground) has no obvious influence on quality of injecting steam. However, the overground main steam pipeline is recommended on considerations of installation and maintenance.

\section{List of Acronyms and Abbreviations}

$\mathrm{CO}_{2}: \quad$ Carbon dioxide

CSS: $\quad$ Cyclic steam stimulation

GIS: $\quad$ Geographic information system

HDPV: Hot gas duct pressure vessel

HTR: High-temperature reactor

HTR-10: 10MW high-temperature gas-cooled reactor

HTR-PM: High-temperature gas-cooled reactor-pebble bed module

HTGR: High-temperature gas-cooled reactor

MHTGR: Module high-temperature gas-cooled reactor

OSR: Oil-steam ratio

RPV: $\quad$ Reactor pressure vessel

SAGD: $\quad$ Steam-assisted gravity drainage

SD: $\quad$ Steam drive

SGPV: $\quad$ Steam generator pressure vessel

SIS: $\quad$ Steam injecting station.

\section{Acknowledgment}

This work has been supported by the Chinese National Science and Technology Major Project (Grant no. ZX06901 and ZX06908).

\section{References}

[1] K. L. Goyal and S. Kumar, "Chapter 11 steamflooding for enhanced oil recovery," Developments in Petroleum Science, vol. 17, pp. 317-349, 1989.

[2] E. Nnaemeka, Petroleum Reservoir Engineering Practice, Prentice Hall, Boston, Mass, USA, 2010.

[3] K. F. Johannes, Petroleum Engineer's Guide to Oil Field Chemicals and Fluids, Elsevier, Oxford, UK, 2012. 
[4] A. R. Kovscek, "Emerging challenges and potential futures for thermally enhanced oil recovery," Journal of Petroleum Science and Engineering. In press.

[5] W. Xianghong, X. Anzhu, and F. Hailiang, "An integrated evaluation on factors affecting the performance of superheated steam huff and puff in heavy oil reservoirs," Petroleum Exploration and Development, vol. 37, no. 5, pp. 608-613, 2010.

[6] T. Zhou, L. Cheng, C. He, Z. Pang, and F. Zhou, "Calculation model of on-way parameters and heating radius in the superheated steam injection wellbore," Petroleum Exploration and Development, vol. 37, no. 1, pp. 83-88, 2010.

[7] E. Baust and I. A. Weisbrodt, "Introducing the hightemperature reactor into the market-status and strategy," Nuclear Engineering and Design, vol. 121, no. 2, pp. 311-315, 1990.

[8] G. Brinkmann, J. Pirson, S. Ehster et al., "Important viewpoints proposed for a safety approach of HTGR reactors in Europe: final results of the EC-funded HTR-L project," Nuclear Engineering and Design, vol. 236, no. 5-6, pp. 463-474, 2006.

[9] R. Kuhr, "HTR's role in process heat applications," Nuclear Engineering and Design, vol. 238, no. 11, pp. 3013-3017, 2008.

[10] R. Reimert and M. Schad, "Process heat from modularized HTR," Nuclear Engineering and Design, vol. 251, pp. 244-251, 2012.

[11] Z. Zhang and Y. Sun, "Economic potential of modular reactor nuclear power plants based on the Chinese HTR-PM project," Nuclear Engineering and Design, vol. 237, no. 23, pp. 22652274, 2007.

[12] Z. Zhang, Z. Wu, D. Wang et al., "Current status and technical description of Chinese $2 \times 250$ MWth HTR-PM demonstration plant," Nuclear Engineering and Design, vol. 239, no. 7, pp. 1212-1219, 2009.

[13] Y. Dong and Z. Gao, "Thermal-hydraulic feasibility analysis on uprating the HTR-PM," Nuclear Engineering and Design, vol. 236, no. 5-6, pp. 510-515, 2006.

[14] Z. Wu, D. Lin, and D. Zhong, "The design features of the HTR10," Nuclear Engineering and Design, vol. 218, no. 1-3, pp. 2532, 2002.

[15] Y. Xu and K. Zuo, "Overview of the $10 \mathrm{MW}$ high temperature gas cooled reactor - test module project," Nuclear Engineering and Design, vol. 218, no. 1-3, pp. 13-23, 2002.

[16] W. Dalrymple, "Beyond electricity," Nuclear Engineering International, vol. 54, no. 660, pp. 34-35, 2009.

[17] Y. Zheng, L. Shi, and Y. Dong, "Thermohydraulic transient studies of the Chinese 200 MWe HTR-PM for loss of forced cooling accidents," Annals of Nuclear Energy, vol. 36, no. 6, pp. 742-751, 2009.

[18] J. Zhang, X. Jia, G. Zeng, Q. Wei, J. Yuan, and R. Liu, "Economic optimization of full life-circle for heavy oil thermal recovery by steam injection process in Karamay oilfield," Xinjiang Pretrolium Geology, vol. 33, no. 1, pp. 80-81, 2012.

[19] L. Dong, "Modeling and analysis of modular hightemperature gas-cooled reactor super-critical unit base on vPower simulation platform," Tsinghua University, pp. 167-173, 2012.

[20] J. Liu, "Research on improving steam thermal efficiency," South West Petroleum University of China, 2003.
[21] J. Ye, Y. Zhou, X. Chen, Y. Ma, F. Li, and Y. Dong, "Simulation of a once-through, helical-coiled steam generator of high temperature gas-cooled reactor," in Proceedings of the 17th International Conference on Nuclear Engineering, (ICONE17 '09), pp. 645-650, Brussels, Belgium, July 2009.

[22] M. Wu, "Analysis and simulation of the thermal-hydraulic processes of primary loop of HTGR," Tsinghua University, pp. 24-39, 2008

[23] Y. Zeng, X. Li, L. Chen, X. Lu, and Q. Wang, "Analysis of the wellbore heat loss in development heavy oil reservoir by steam injection," Drilling \& Production Technology, vol. 29, no. 4, pp. 44-46, 2006.

[24] X. Liu, M. Li, and Y. Jian, "Simulative experimental research on the thermal insulation construction of the gas injecting pipeline using thick oil heat extracting," Pipeline Technique and Equipment, no. 2, pp. 8-10, 2000. 

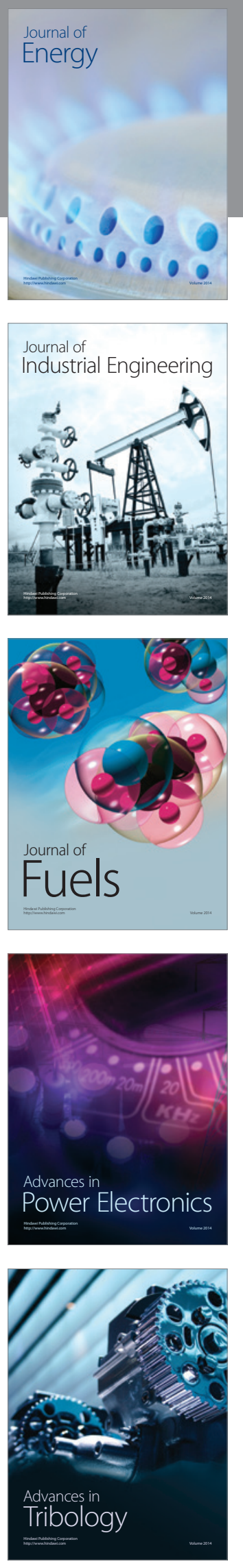
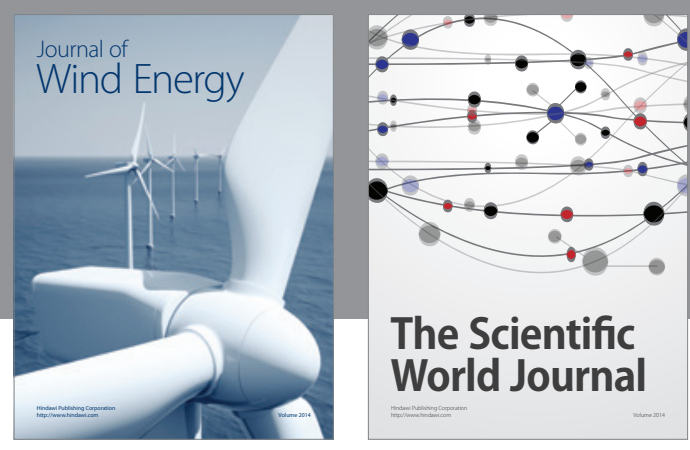

The Scientific World Journal

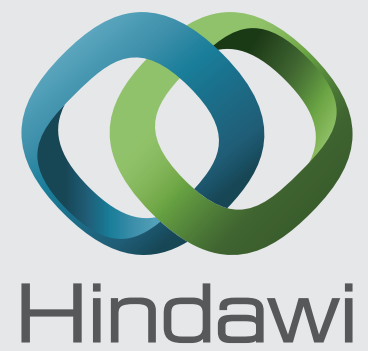

Submit your manuscripts at http://www.hindawi.com
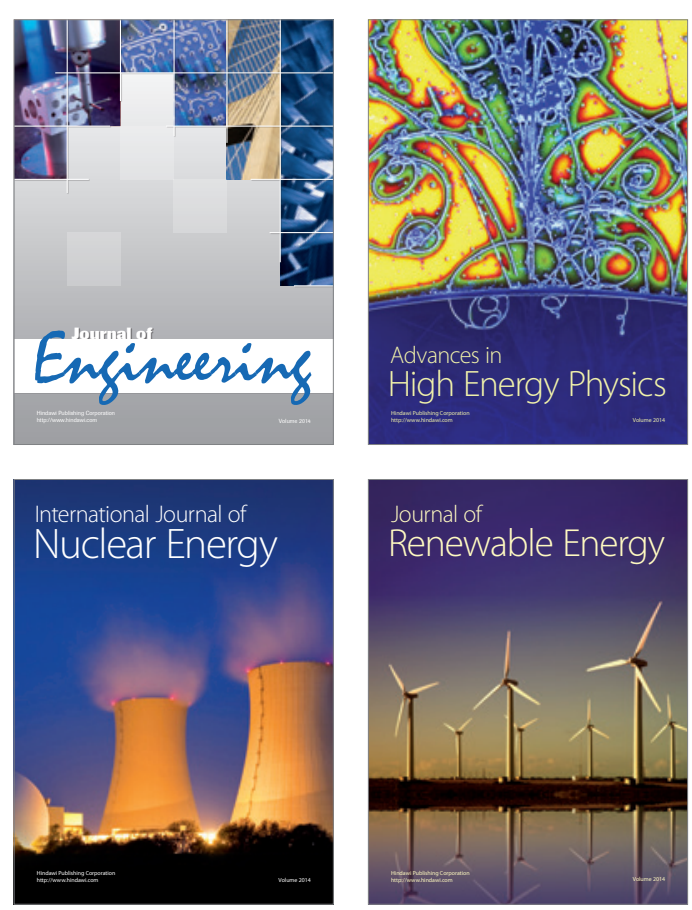

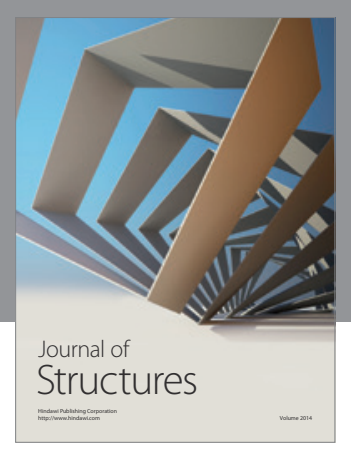

Rotating
Mechinery
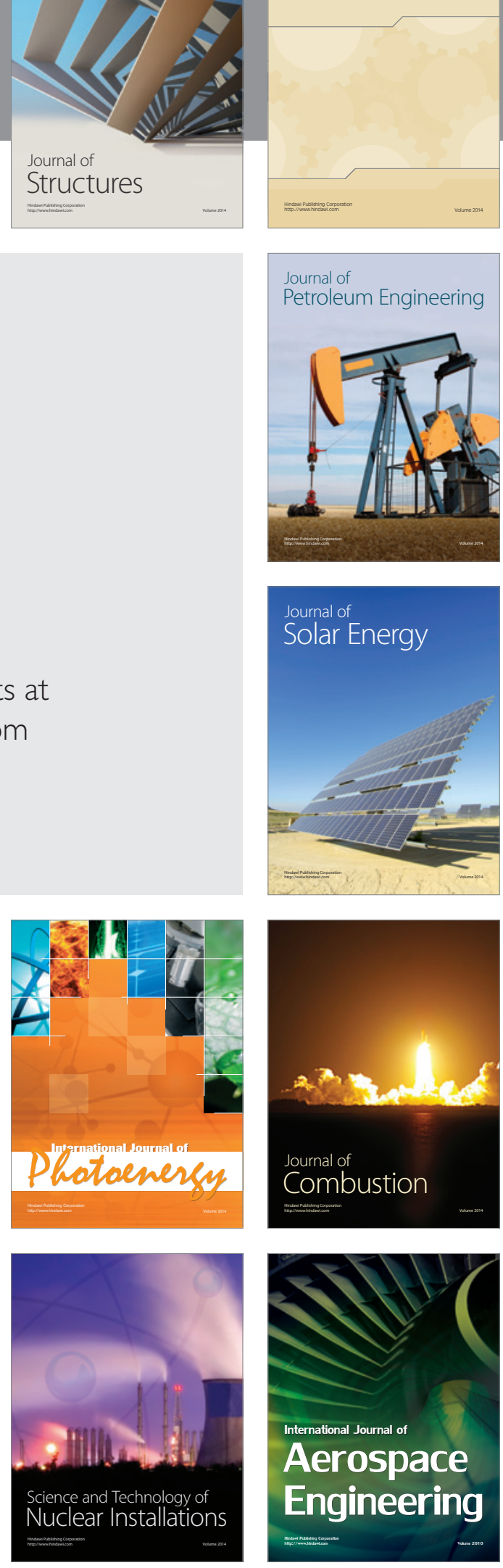